\title{
Managing Networks in Business Organizations
}

\author{
Dangis Gudelis \\ Mykolas Romeris University, Vilnius
}

Lithuania

\section{Introduction}

Business organizations are embedded in many different network relationships (Granovetter 1983). Companies establish enduring relationships with their clients and suppliers, they collaborate with other companies in order to increase their market power, save costs, improve effectiveness, serve problems specific to customers, develop new technologies and for many other reasons (De Man 2004, 20). Business organizations are also involved in relationships with government institutions and non-governmental organizations for various purposes, such as lobbying, public-private partnerships, sharing of information or charity.

There are certain characteristics common to all types of the network relationships. First, they are oriented to some common goal which is beneficial to the partners who are not able to achieve the goal by acting alone. Thus the partners are supposed to comply to a formal or informal agreement on the importance of this goal. Second, the network relationships imply commitments and responsibilities of the partners involved to act according to the agreement. Thus companies taking part in various networks act not only for the sake of profit but they undertake certain responsibilities.

The article will discuss theoretical implications of the network management approach based on two behavioral assumptions: bounded rationality and bounded morality. Herbert's Simon's theory of administrative behavior (Simon 1997) will be extended in order to explain principles, modes and mechanisms of network organization. Recommendations and prescriptions for network managers of business organizations, including identification of various types of business networks, network analysis, development of network management strategies, integrating them with general organizational processes, will be developed.

\section{Theoretical basis for the network management}

\subsection{Theoretical assumptions}

The network management approach is based on two assumptions: the assumption of limits of human rationality and the assumption of bounded human morality. The assumption of bounded rationality means that individuals in their decision making are not able to evaluate all possible alternatives for those decisions, foresee their consequences, and choose the most optimal alternative promising the best results. Bounded rationality is conditioned by limitations of human mental abilities to process information, to focus attention, to 
memorize, by habits and frames of thought (Simon 1997; Kahneman and Tversky 1979). Limits of human rationality are widely researched in cognitive psychology, experimental economics, the assumption of bounded rationality as an alternative to the neoclassical concept of the rational individual is widely used in organization theory, theory of social choice, public administration and public policy studies.

The network management perspective implies that business organizations as any other individuals or organizations operating in networks raise objectives and tasks, deliberate on measures to achieve them, take decisions and act in accordance with their specific frame of thinking and the information available, which means that their decisions and actions are not necessarily the best way possible. Due to bounded rationality network actors do not realize and do not see many opportunities for their action, thus it could be claimed that the potential of networks is not fully used. This does not mean necessarily that there are better ways of operating than those chosen by participants in the network, but the attitude based on the assumption of bounded rationality encourages the search of alternative ways of thinking and action and the openness to change and improvement. This approach also enables the deliberation on ways how to increase the rationality of network participants.

The assumption of bounded morality is no less important for the network management approach. It should not be identified with the assumption of moral opportunism, which states that individuals pursue their own interests with guile, involving some kind of deliberate deceit and the absence of moral restraint, the assumption important for transaction cost economics (Williamson 1975). Bounded morality implies that individuals obtain the moral sense and the ability to act according to moral obligations and responsibility, but such moral motives are limited by natural selfishness, bad habits, the weakness of will (akrasia), and ignorance (the failure to anticipate the negative consequences of certain behavior, frames of thought, distorting the understanding of moral values and norms). The approach that human morality is limited opens opportunities for the search of means such as moral education or the development of circumstances favorable for moral behavior by which human beings could be encouraged to act morally in different situations.

Moral behavior in the network management perspective is defined as behavior opposite to selfish behavior, when one's action is motivated by the common goal, common good or by obligations to principles, values, norms or agreements. Human relations and joint action are often conditioned by formal or informal agreements, commitments or common goals. Therefore, it can be claimed that networks provide a framework for the moral behavior and human morality is directly related to his or her involvement in various social networks - the human being in deciding to enter a social network, commits himself or herself to certain common goals and agreements at the expense of his or her personal interests. Networks which essential feature is the mutual trust would be impossible without the moral commitment of their participants.

Business organizations, from small enterprises to big corporations, are embedded in various social networks involving public, non-governmental and private organizations; they take part in various associations, clusters, and partnerships. Business organizations develop long-term relationships with suppliers and clients and are involved in various charity activities. It would not be exaggerating to say that the network embeddedness is a reality of each business organization. Each business organization has to take this reality seriously if it wants to be successful in its business. The network embeddedness creates challenges, risks 
and opportunities to management of business organizations. Different network relationships have to be managed.

The network management approach is developed on the basis of recognition that there is a need to manage external relationships of business organizations. The theoretical basis for the network management approach is elaborated from the Simon's theory of administrative behavior (Simon 1997). This approach could be compared with other theories explaining external relationships of business organizations such as the open system theory (Katz and Kahn 1966). The open system theory examines organizations as open systems interacting with their environment. There are three basic differences between the open system theory and the network management approach. First, the open system theory is a theory explaining organizations, while the network management approach is prescriptive. Second, the organizational environment is understood broadly from the perspective of the open system theory while the network management approach focuses only on those elements of organizational environment which include individuals and organizations. Third, the network management approach, unlike the holistic open system theory, is elaborated on the basis of behavioral assumptions of bounded rationality and morality.

The network management approach could also be compared with the stakeholder theory (Freeman 1984). From the perspective of the stakeholder theory stakeholders are those who have stake in the organizations, they are already present and business organizations do not have an opportunity to freely choose their stakeholders. Stakeholders are organizations or individuals to whom the business organizations have moral obligations. The network management approach implies that business organizations could choose many of their partners voluntarily. Business organizations could enter or leave existing networks, change them, or create new networks. Thus moral responsibility is mutual because there are expectations that network partners also will be responsible. In the stakeholder theory stakeholders bound business organizations with moral obligations, however, this theory does not take into account the issues of moral responsibility of stakeholders themselves (see Table 1).

\begin{tabular}{|l|l|l|}
\hline & \multicolumn{1}{|c|}{ Network partners } & \multicolumn{1}{c|}{ Stakeholders } \\
\hline Necessity of relationship & free choice & obligatory \\
\hline Moral responsibility & mutual & unilateral \\
\hline
\end{tabular}

Created by the author

Table 1. Comparison between the network management and the stakeholder theory

The approach of the corporate social responsibility which has been at the focus of business management theory and practice during the last thirty years (Carroll 1979; Schwartz and Carroll 2003; Jamali 2008; Carroll and Shabana 2010) could be derived from the assumption of network embeddedness. Stakeholder and network management approaches handle issues of corporate social responsibility in different ways. Stakeholder theory implies that companies are socially responsible if they take interests of their stakeholders seriously. Obligations for responsible activities stem from the implicit social contract between a company and various stakeholder groups. The contract does not have to be a real negotiated agreement between parties with different interests. It is sufficient that managers of the 
company presuppose interests of their stakeholders and make decisions concerning their commitments to the imagined contract. The network management approach suggests that companies make socially responsible commitments to act according to an agreement achieved by network actors negotiating a common goal.

\subsection{Network equilibrium}

Organizations take part in various networks only if their network activities contribute to the achievement of their organizational goals. Thus the important question is how the organizational goals are matched to the common goals of the networks. Here the concept of the network equilibrium could be formulated following the idea of the organizational equilibrium developed by Chester Bernard and later elaborated by Herbert Simon (Simon 1997, 141). As well as individuals receive direct or indirect benefits from their participation in organizational activities, the participation of business organizations in network activities contributes directly or indirectly to their organizational goals. If the goals set in a network are valuable for the business organization the contribution is direct (as in the most cases of business participation in policy networks) and it could be said that the network has positive externalities on the achievement of the goals of the business organization. The contribution is indirect in the cases where business organizations receive rewards for their participation (e.g. payments to experts for sharing their know-how in knowledge networks). On the other hand, the network will exist if there are common goals for the achievement of which each network member is obliged to contribute something. Network participants consider the potential contribution of a new member to the network goals before making a decision concerning its membership. If a network participant fails to contribute to the common goal other network members could consider to exclude it from the network. Thus each business organization while deliberating whether to enter or leave a network assesses how it could contribute to the network and what it could receive from it.

How could business organizations contribute to the achievement of network goals? There are two options. Business organizations either conduct some specific activities which they would not have conducted if they had not took part in the network or their contribution is ensured without any costs additional to their activities which are directed to the achievement of their organizational goals. The second option points to some positive effects (or positive externalities) on network goals that are generated by business organizations pursuing their organizational goals.

The network management approach which is based on the assumption of bounded morality aims to reconsider the problem of collective action that was identified by Mancur Olson (Olson 1965). Olson questioned the feasibility of any collective activity if indirect rewards to participants of the collective activity are not provided. Olson argued that any collective action resembles the Prisoner's Dilemma situation where individual actors have incentives to free ride, that is, to choose a non-cooperative course of action which undermines the achievement of any collective goal. Following the logic of collective action business organizations will not be ready to experience any additional costs necessary for the achievement of network goals and that will result in disintegrating of most interorganizational networks (except thoose which are supported by positive externalities of their members). However, the assumption of bounded morality implies that, although there 
is a risk of free-riding, there is also a potential for moral actions, that is, actions based on obligations to the network goal and on trust that other network members will act according to their own obligations.

\subsection{Modes of network influence}

Simon examined authority and communication as external modes of organizational influence and the criterion of efficiency and loyalty or organizational identification as internal modes of organizational influence (Simon 1997, 9). Thus it makes sense to identify four modes of network influence which affect decisions and behavior of individual network members (in this case, business organizations and their partners in various networks): authority, communication, the criterion of efficiency and network loyalty. It is also important to notice that those modes serve for the ensurance of coordination in networks.

One of external modes of network influence is authority. According to Simon, authority could be defined as a relationship between superior and subordinate (Simon 1997, 179). Superiors realize their authority by giving commands, that is, imperatives to choose a certain behavior alternative, which are followed by subordinates. However, although authority relationships in hierarchical organizations are usually clearly defined, the exercise of authority in networks is less obvious. Business organizations join networks voluntarily, thus the issue of authority, that is, the issue about who will give commands and who will obey them, how accountability will be exercised, and what sanctions will be, in the networks is a matter of the agreement among the network actors. There are two factors that might influence the appointment of the ,superior' among network members. First, the network actor who possesses resources such as finances or expertise which other network actors are dependent on is more likely to become the ,superior'. Second, the role of the ,superior' might be designated to the network actor who has initiated the network. In many participatory networks, however, authority relationships are replaced by other kinds of influence such as persuasion and suggestion. It could also be assumed that the area of acceptance that determines which decisions made by ,superiors' ,subordinates' are willing to accept (Simon 1997, 185) is much narrower in networks than in organizations.

Another external mode of network influence is communication. Simon defined communication in organizations as a two-way process: it comprehends the transmittal of orders, information and advice to a decision making center and from this center to other parts of organization (Simon 1997, 208). He also distinguished between vertical and horizontal, formal and informal communication. Communication in networks is organized in a manner less formal and hierachical than in most organizations, however, some networks develop formal procedures and elements of hierarchical relationships. Channels of communication in networks usually determine structural relationships between network members. There are various media of formal communication. Simon identified several media of formal communication: oral communication, memoranda and letters, paper flow, records and reports, manuals (Simon 1997, 211 - 213). Taking into account the development of information and communication technologies in the past thirty years, the list of various media of communication should be definitely expanded: such media as mobile phones, internet, electronic mails, web-based social networks, videoconferencing systems, etc. have become widely used tools of both formal and informal communication. 
Simon identifies the criterion of efficiency as an internal mode of organizational influence, that is, a decisional premise that the individual supplies himself or herself while making decisions in organizational settings. The criterion of efficiency dictates the individual to select the alternative which yields the greatest net return to the organization. This criterion could be defined in two ways: either as the maximization of income, if costs are considered as fixed or as the minimization of cost, if income is considered as fixed (Simon 1997, 250). What would be the implications of this criterion for decision making of business organizations in various governed networks? As it was mentioned above, in the networks business organizations have to balance organizational goals with the goals the network members have agreed on. The criterion of efficiency is a condition for the achievement of both organizational and network goals. If participation in the network do not seem to be efficient with regard to the profit maximization goal of the business organization, the organization might choose to leave the network. On the other hand, if the business organization does not act efficiently from the point of view of the network, it might be expeled from the network by other network members. Thus the business organizations have both internal and external incentives to the efficiency in networks, they also have expectations that partners in the networks will also be guided by such incentives. In order for a network to be efficient it is important for the business organizations to design performance measurement systems with indicators reflecting the network goals and resources necessary for their achievement. Such systems should be integrated with the performance measurement systems of the business organizations themselves.

Loyalty to network values and goals is another internal mode of network influence. As it was observed by Simon with regard to organizations (Simon 1997, 278), values of a certain network become internalized by its individual members. Business organizations by joining a network commit themselves to be loyal to goals and values of the network. Within networks business organizations identify themselves with certain roles which specify the particular values, facts and alternatives upon which the decisions of the organizations are to be based (Simon 1997, 278). The assumptions of bounded rationality and morality imply that behavior of business organizations, including their decisions to join networks, is determined by various frames which might result in sub-optimal knowledge and distorted values of the networks. In such cases network values might be undesirable from the point of view of more general social values. Simon explains this value conflict by introducing the distinction between subjective and objective rationality (Simon 1997, 85). It also makes sense to distinguish between subjective and objective morality. Some activities of business organizations are moral subjectively, that is, good from the point of view of organizations themselves, but immoral objectively, from the perspective of wider social consequences.

Those four modes of network influence have a function to secure network coordination. Coordination is necessary in order for various networks to be effective. There are different forms of coordination in networks. According to Simon, the simplest form of coordination is self-coordination, when individual participants adjust their activities by observing what others are doing. Another form is the examination of their own alternatives and the alternatives available to the group (or network). And the last, the most complex, form of coordination is based on expectations of the courses of action that will be followed by other actors which is achieved in the process of planning (Simon 1997, 113). Planning and review are two administrative techniques that are very important for coordinated decision making both in organizations (Simon 1997, 312) and in networks. In the following chapter it will be 
examined how these two techniques could be applied in the context of network management.

\section{Strategic network management}

\subsection{Types of networks}

In order to assess the opportunties for a business organization to take part in various networks and to develop strategies of network management it is important to understand what options for such network participation are available. Thus the distinction between governed networks and passive networks will be discussed here and various types of networks will be examined. The governed networks at least some members of which are business organizations include policy networks, knowledge networks, investment networks, service delivery networks, client networks, producer - supplier networks. (see Table 2). What is specific about all of them as governed networks is that they are mobilized, their members make agreements on particuliar goals and measures how to achieve those goals as well as moral commitments to act according to the agreements. Those networks have properties similar to those of organizations such as goal orientation and division of tasks and they are being governed more or less by the same internal and external modes of influence which were described above.

Policy networks are the networks of actors taking part in processes of policy formation and implementation (Rhodes 1997; Kickert, Klijn, and Koppenjan 1997). Business organizations usually take part in various policy networks in order to protect their interests which might be affected by different public policies. Those networks are either informal or organized by special associations of business interest representation such as the association of industrialists, the union of employers, etc. Business organizations join policy networks if they feel that their interests could be better protected by cooperating with other organizations than by acting alone. In some cases policy networks might include also government institutions and non-governmental organizations - then the purpose of such network is not the protection of business interests but the achievement of some benefits to society with the help of certain public policies.

Another type of governed networks is knowledge networks. Knowledge networks are formed around the goal to accumulate and share knowledge which could be used for the public benefit. Those networks might include business organizations along with schools, universities, government agencies and other actors, however, the purpose of them is not to find and articulate solutions to one or another policy issue though the knowledge produced in those networks could contribute to public policies indirectly. Examples of knowledge networks are various centers of research and innovations, the centers of excellence.

The other type of the governed networks is investment networks. Members of those networks join together for the purpose of investment into various business projects. The networks might include corporate and individual investors as well as governments. Public private partnerships are widely studied examples of investment networks. Other examples are joint stock companies, investment funds, cooperatives. Investment networks serve the public benefit because investments are beneficial to the society - either directly in the case of public-private partnerships or indirectly as positive externalities contributing to the economic growth. 
Service delivery networks could also be identified as a type of governed networks. Business organizations along with public and nongovernmental organizations providing services as well as individual volunteers might cooperate for the aim to cope with some social or environmental problems. An example of such service delivery network is the 'Food bank', a project involving nongovernmental organizations and volunteers as well as shopping centers and mobilizing them for the purpose of collection and distribution of food products to poor people in Lithuania.

Other two types of the governed networks - client networks and producer-supplier networks - are related with the specific business environment. Business organizations develop long-term relationships with clients and suppliers in order to achieve their purposes of product quality, efficiency, and profit maximization.

\begin{tabular}{|l|l|}
\hline \multicolumn{1}{|c|}{ Governed networks } & \multicolumn{1}{c|}{ Passive networks } \\
\hline $\begin{array}{l}\text { policy networks } \\
\text { knowledge networks }\end{array}$ & common norms networks \\
service deliery networks & common interest networks \\
investment networks & common identity networks \\
client networks & common values networks \\
producer-supplier networks & resource dependence networks \\
\hline
\end{tabular}

\section{Created by the author}

Table 2. Types of networks

On the other hand, passive networks are systems of interrelationships between various organizations and individuals based either on actual interactions or on some communality. Passive networks lack the characteristics of organizations - they are not oriented to the common goals, their members do not realize the opportunities to do something together. Several types of passive networks could be identified: common norms networks, common interest networks, common identity networks, common values networks, resource dependence networks. The important feature of the passive networks is their potential to be transformed into governed networks.

The common norms networks include individuals and organizations regulated by the same legal norms or rules. For example, there are networks of charity funds, networks of banks, networks of universities, networks of employees or consumers and so on. Quite often it is a case that those organizations or individuals have nothing in common except that they have the same legal status, comply to the same regulations or are obliged to pay the same taxes. Such networks usually are loose and passive, however, they have a potential to be transformed into policy networks advocating public policies that could benefit to the interests of the network members.

The first step of such transformation is the realization of the common interest which is shared by all members of common norms networks. By realizing such common interest the common norms' networks are transformed to common interest networks. The next step of mobilization is the agreement on the common goal and means to achieve the goal as well as the obligation to act according to the agreement. Such is the transformation process resulting in the formation of policy networks. 
There are also common identity networks which members share the same ethnic, religious, professional, gender or other identity. Those networks are loose and not mobilized until there is no threat to identities of their members. When there is a threat - for example, occupation of a nation by a foreign force - members of the network realize that they have the common interest and mobilize for the goal to protect their identity.

Common values networks usually are more integrated than common norms networks or common identity networks because their members share the understanding about values and principles guiding their actions. However, the agreement on goals for the joined action and what ought to be done is absent thus such networks remain inactive. To activate them and transform them into governed networks it is necessary to communicate the knowledge about policy problems, goals and actions needed to handle them. Sometimes those networks correspond to networks of certain identities, however, in many cases commitment to some values or principles is not dependent on a specific identity. An example of a common values network including business organizations could be a network of business organizations owned by diaspora entrepreneurs who are committed to the value to help their home country.

Another type of passive networks is resource dependence networks. Rhodes (1997) characterized resource dependence as an essential feature of policy networks. Interactions between suppliers and producers, producers and consumers, sellers and buyers, teachers and learners, principals and agents, contracting parties within different kinds of contracts create relationships of dependence between those who possess financial, material, informational, legal or other resources and those who exploit the resources for various activities. However, resource dependence networks are not necessarily governed networks. Along to the other inactive networks those networks also have to be transformed into the governed networks by agreeing on a joint goal and actions among their members.

In sum it could be said that the one of the tasks of network management is to mobilize networks - that is, to transform passive networks into governed networks for the governed networks which are goal oriented have the greater potential to be effective. Business organizations could initiate such transformation or they could support the initiatives of other organizations or individuals.

\subsection{Network analysis and network strategies}

How could network relationships be managed by business organizations? Managers of a business organization, aiming to improve relationships of their organization with various network partners, could choose to conduct the network analysis and develop a network management strategy. This strategy should be integrated into the general strategy of the business organization.

The network analysis should be conducted in order to examine the functionality and potential of networks the business organization is already involved in as well as to assess the potential of various alternative network relationships. The network analysis could apply the SWOT method for the assessment of strenghs, weaknesses, opportunities and threats of the organization's participation in various networks.

The network analysis could start by identifying how general organizational processes human resource management, financial management, production, service delivery, process 
management, selling, marketing processes - depend on various network relationships. The types of networks which the business organizations is related with should also be identified. Then the network analysts should examine each of those relationships by answering such questions:

- Is the network governed or passive?

- What common goals are set in the network?

- Is there an agreement on specific actions to achieve the network goals?

- What are obligations of the business organization and its partners in the network?

- What is the impact of the organizational goals on the network goals?

- What is the impact of the network goals on the goals and processes of the business organization?

The general organizational processes are usually interrelated with various networks. For example, human resource management processes are dependent on the organization's relationships with other organizations through knowledge networks for it opens opportunities for the organization to acquire new knowledge and improve competences of its employees. However, there is also a threat that the participation in a network could make conditions for competitors to learn from the know-how of the business organization.

The financial management processes (budgeting, accounting, etc.) are also embedded in various network relationships. When the business organization joins a network (for example, an investment network), the task of financial management becomes to plan, allocate and monitor financial resources for the collaborative activities. Opportunities of the network participation could be the reduction of investment risk or benefits of collective deliberation on the investment decisions. The potential threats such as the dependence on the irresponsible partner activities should also be taken into account.

Network partners of the business organizations (for example, partners participating in service delivery networks or producer-supplier networks) should be integrated into production or service delivery processes ensuring that network and organizational goals will be achieved; it is the task of process management. The network analysis could reveal the potential of such integration. However, the threat is the low degree of integration and coordination of those processes.

Client management processes (marketing, etc.) are dependent on network relationships with clients of the business organization. There are both opportunities of participation for the business organization in client networks (guaranteed sales of the products, long-term contracts, etc.) and threats to loose new markets and clients as well as the ability to innovate.

After the network analysis and the assessment of the potential of network participation managers of the business organization should develop the network management strategy. They could choose one of several alternative strategies:

- $\quad$ strategy of building network relationships;

- $\quad$ strategy of mobilizing network relationships;

- $\quad$ strategy of sustaining network relationships;

- $\quad$ strategy of breaking network relationships.

No matter which alternative will be chosen the network management strategy should become a consistent part of the general strategy of the business organization (Figure 1). It 


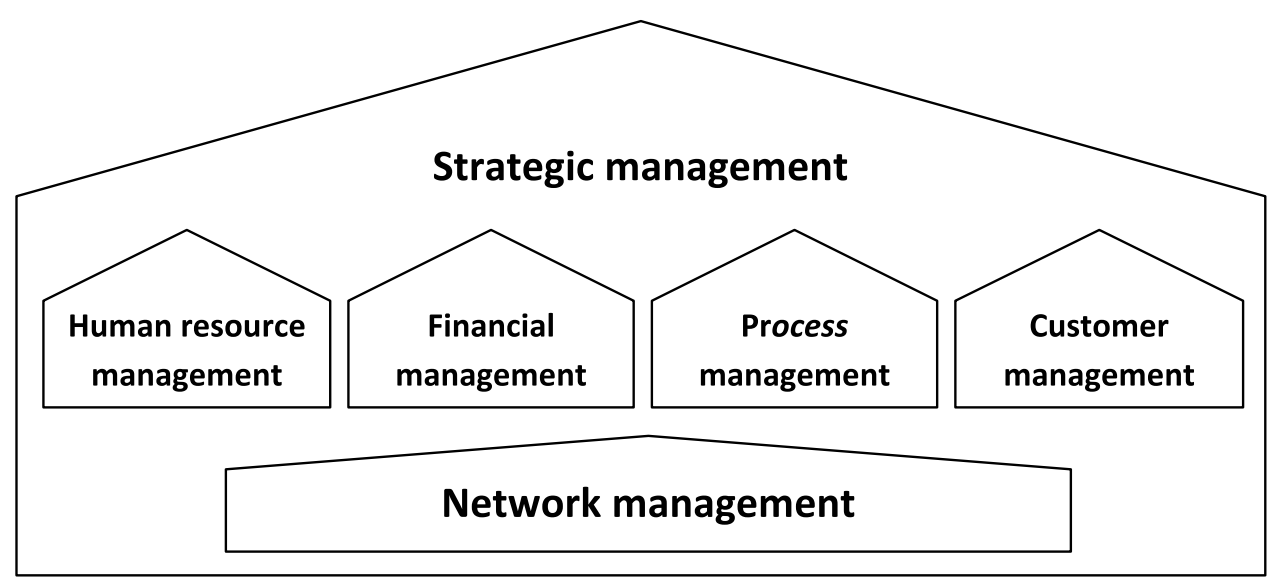

Created by the author

Fig. 1. Integration of network management and strategic management in business organizations

also should be coordinated with the plans of the governed networks themselves if such plans are developed.

The strategy of building network relationships could be opted for if the business organization does not take part in some networks and the network analysis reveals that there are potential benefits of such network relationships. There are two ways to build network relationships - either to join already functioning network or initiate a new network. The following steps to build an efficient new network could be considered:

- $\quad$ Identify the mission of the network;

- Identify potential partners and their interests;

- Introduce your own organization and the mission of the network to potential partners;

- Select the partners of the network;

- Set and negotiate the plan of the network: common goals and means to achieve these goals;

- Identify resources needed for the achievement of the common goal;

- Make commitments to act and act according to the commitments;

- Monitor and evaluate actions of partners and your own organization;

- Monitor and evaluate the achievement of the common goals.

The strategy of mobilizing network relationships could be chosen if the network analysis indicates that the business organization is a part of some passive network which has the potential to be transformed into a governed network. In this case mobilization of a network could include the same steps as in the strategy of network building. However, the mobilization strategy could also be applied in order to make the governed networks more effective and efficient. Networks could be made more effective and efficient by applying various modes of network influence.

If the network analysis reveals a satisfactory condition of network participation of the business organization, the strategy of sustaining network relationships could be elaborated. 
The strategy of breaking network relationships could be chosen if it is revealed that participation in networks becomes an obstacle to the achievement of the major organizational goals.

\section{Conclusions}

The network management approach discussed in this article has both theoretical and practical implications. The statements about mechanisms of network formation and types of networks elaborated on the assumptions of bounded rationality and morality could make a platform for the empirical or experimental research. The normative aspects of the network management such as democracy in networks are another important field of inquiry. What concerns practical significance of the network management approach, it could be noticed that business organizations could become more sensitive to opportunities of collaboration and to the issues of moral (social) responsibility if they start to manage their network relationships.

\section{References}

Carroll, Archie B. 1979. A Three-Dimensional Conceptual Model of Corporate Performance. Academy of Management Review 4 (4):497-505.

Carroll, Archie B., and Kareem M. Shabana. 2010. The Business Case for Corporate Social Responsibility: A Review of Concepts, Research and Practice. International Journal of Management Reviews 12 (1):85-105.

De Man, Ard-Pieter. 2004. The Network Economy: Strategy, Structure, and Management. Cheltenham, UK and Northampton, MA:: Edward Elgar Publishing.

Freeman, Edward R. 1984. Strategic management: a stakeholder approach. Boston: Pitman.

Granovetter, Mark. 1983. The strength of weak ties: a network theory revisited. Sociological Theory:201.

Jamali, Dima. 2008. A Stakeholder Approach to Corporate Social Responsibility: A Fresh Perspective into Theory and Practice. Journal of Business Ethics 82 (1):213-231.

Kahneman, Daniel, and Amos Tversky. 1979. Prospect Theory: An Analysis of Decision under Risk. In Econometrica.

Katz, Daniel, and Robert L. Kahn. 1966. The social psychology of organizations. New York: Wiley.

Kickert, Walter J. M., Erik-Hans Klijn, and Joop F. M. Koppenjan. 1997. Managing Complex Networks: Strategies for the Public Sector. London: Sage Publications.

Olson, Mancur. 1965. The Logic of Collective Action. Cambridge: Cambridge University Press.

Rhodes, R.W.A. 1997. Understanding Governance: Policy Networks, Reflexivity and Accountability. Buckingham, Philadelphia: Open University Press.

Schwartz, Mark S., and Archie B. Carroll. 2003. Corporate social responsibility: a threedomain approach. Business Ethics Quarterly 13 (4):503-530.

Simon, Herbert A. 1997. Administrative Behavior: A Study of Decision-Making Processes in Administrative Organizations. New York, NY: Free Press.

Williamson, Oliver E. 1975. Markets and Hierarchies. New York: Free Press. 


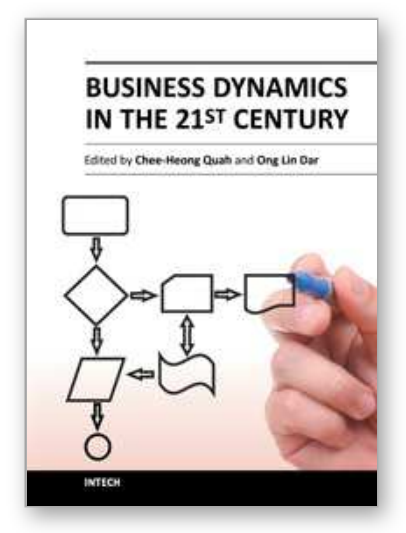

\author{
Business Dynamics in the 21st Century \\ Edited by Dr. Chee-Heong Quah
}

ISBN 978-953-51-0628-9

Hard cover, 260 pages

Publisher InTech

Published online 23, May, 2012

Published in print edition May, 2012

In this 21st century of opportunity and turbulence, business firms need to equip themselves with new competencies that were never thought of before. For this reason, this book is timely as it introduces new insights into new problems in the aspects of performance and quality improvement, networking and logistics in the interconnected world, as well as developments in monetary and financial environment surrounding private enterprises today. Readers shall find that reading this book is an enlightening and pleasant experience, as the discussions are delivered in a clear, straightforward, and "no-frills" manner - suitable to academics and practitioners. If desired, the book can serve as an additional piece of reference for teaching and research in business and economics.

\title{
How to reference
}

In order to correctly reference this scholarly work, feel free to copy and paste the following:

Dangis Gudelis (2012). Managing Networks in Business Organizations, Business Dynamics in the 21st Century, Dr. Chee-Heong Quah (Ed.), ISBN: 978-953-51-0628-9, InTech, Available from: http://www.intechopen.com/books/business-dynamics-in-the-21st-century/managing-networks-in-businessorganizations

\section{INTECH}

open science | open minds

\section{InTech Europe}

University Campus STeP Ri

Slavka Krautzeka 83/A

51000 Rijeka, Croatia

Phone: +385 (51) 770447

Fax: +385 (51) 686166

www.intechopen.com

\section{InTech China}

Unit 405, Office Block, Hotel Equatorial Shanghai

No.65, Yan An Road (West), Shanghai, 200040, China

中国上海市延安西路65号上海国际贵都大饭店办公楼 405 单元

Phone: +86-21-62489820

Fax: +86-21-62489821 
(C) 2012 The Author(s). Licensee IntechOpen. This is an open access article distributed under the terms of the Creative Commons Attribution 3.0 License, which permits unrestricted use, distribution, and reproduction in any medium, provided the original work is properly cited. 